\title{
Implementation simulink modeling to analysis the transient cases and torque speed characteristic in a three phase induction motors
}

\author{
Omar M. Al-Barbarawi ${ }^{1}$, Ghazi M. Qaryouti ${ }^{2}$ \\ ${ }^{1}$ Department of Electrical Engineering, Faculty of Engineering Technology, Al Balqa' Applied University, Jordan \\ ${ }^{2}$ Department of Mechatronics Engineering, Faculty of Engineering Technology, Al Balqa' Applied University, Jordan
}

\begin{tabular}{l} 
Article Info \\
\hline Article history: \\
Received Aug 28, 2018 \\
Revised May 11, 2019 \\
Accepted Jun 28, 2019 \\
\hline
\end{tabular}

\section{Keywords:}

Balanced and unbalanced Induction motor Mathematical modeling Simulink Torque-Speed

\begin{abstract}
In this research, a mathematical model has been developed for investigating the dynamic behavior of a three-phase induction motor. The steady and transient states of the motor has been analyzed for both balanced and unbalanced voltage supply. The behavior of the Torque-Speed characteristics at various conditions has been studied. Matlab/Simulink models are proposed to investigate the dynamic behavior of the motor using d-q axis theory in the reference frame. These models investigate the behavior of the induction motor parameters. In addition, they enable the researcher to work out or look into any variable for an induction machine parameter. As an example, the potential difference, current, flux, speed and torque as a function of time in transient and steady state. The Microsoft Excel has been used by utilizing the proportion between the formulae of the electromagnetic torque equation (Tem) and maximum torque equation (Tmax). The behavior of the Torque-Speed characteristics for a 3-phase induction motor has been studied and analyzed. Utilizing these models the force of the various parameters on the dynamic behavior of the motor has been investigated These models could be utilized for a wide range of motors which has a various horse powers, that is required in a scientific inquiry and practical applications.
\end{abstract}

Copyright $(0) 2019$ Institute of Advanced Engineering and Science. All rights reserved.

\section{Corresponding Author:}

Omar M. Al-Barbarawi,

Department of Electrical and Computer Engineering,

Faculty of Engineering Technology, Al Balqa' Applied University, Jordan.

Email:omaralbarbarawi@bau.edu.jo

\section{INTRODUCTION}

The induction motors are widely applied in industrial applications as a mean for converting electric power to mechanical work due to its hardiness, self-static stability during load variation, and good self-starting capability, low maintenance requirement and rugged design [1-2]. And it has been risen from being a constant speed motors to being a variable speed motor with the progress of power electronics [3]. Also, the induction motor is reckoned as a nonlinear dynamic system. So, studying and analyzing the performance, of the IM is very significant, to describing the behavior of the motor during operating under different cases such as startup, transient cases, steady state, when it is fed from balanced and unbalanced voltages or at any drop voltage in source or any other severe transient operations.

Where the performance of an IM is weakening when operating under unbalance voltage conditions. Voltage unbalance stimulates increased motor losses and reduces motor efficiency, which results in increased heat generation that may lead to early motor damage [4-5]. The reduced efficiency increases the system load on the power source which unnecessarily depletes the energy reserve of the power plant [5]. Voltage unbalance produces a magnetic flux that opposes the main flux, and this causes a large oscillatory currents and a large oscillatory torque, at twice the frequency of the supply. Produces drop voltage, and can even generate higher 
harmonics, which contribute to distortion the characteristics in power systems Also, the opposing flux leads to the generation of negative sequence currents which is lead to increased motor losses [9], and heat production which may result in early failure the stator windings $[6-7,14]$. The power systems are usually designed to have a balanced and equal voltage value per phase, but due to operational realities such as non-linear loads [9], heavy commercial and industrial loads, network line disturbances, the ratio of three phase to single phase loads [1], transformer faults, line transposition issues, and other severe transient operations with varying scores and so forth. This abnormal supply condition is referred to as voltage unbalance [4-5]. Voltage unbalance exists in most supply networks [9]. The dynamic-mechanical characteristics of the motor depend on the supplying voltage, winding parameters, the HP of the motor and the value of the rotor resistance [4]. In this paper, differential (1) to (4) and the equivalent circuit see Figure 1, which is a nonlinear equation as a mathematical model to study and analysis the behavior of the induction motors (IM) when operated under balanced and unbalanced supplying voltage, and with specific faults in stator and rotor side and simulation this model using MATLAB/Simulink [10-12].

In this research the mathematical model using to simulation are based on the $\mathrm{d}$-q axis theory in stationary reference frame and synchronously rotating reference frame to study and analysis the dynamic static performance and to analyze the effect of unbalanced voltage, which feed the induction motor during transient behavior and steady - state performances and the best approach used to calculate the start - up, speed electromagnetic torque, stator currents and rotor currents of the induction motor [16-18]. Matlab/Simulink is a very useful to be used to call the dynamic behavior of the machines for high accuracy, in a really short time period for transient causes [8-10]. The simulation results which are computed and plotted as a function of time on form cartographic curves during the functioning process of the motor, as will be demonstrated afterwards. Likewise, in this report, we have examined and analyzed mathematical model using in Simulation Microsoft program, for a torque -velocity characteristics of the induction machines and draw it, when motors start with the full line voltage, by inserting an external variable resistor in series with rotor circuit. This starter is used with a wound rotor induction motor to load [3-6]. The proposed Mathematical models could be utilized for a wide range of motors which has a various horse power ratings needed in scientific research and mathematical applications. The Simulation has been employed to investigate the behavior of a 5, 46, $480 \mathrm{HP}$ induction motors by using his parameters as indicated in Table 1. The Simulation results have been represented and compared the results between this motor.

\section{MODELING OF INDUCTION MOTOR}

The equations needed to study and analyze the transient cases and determine the behavior of any induction motor are the dynamic differential (5) and (6) and the equivalent circuit in Figure 1 which that can describe the performance of the IM at any of transient case. In this research the dynamic differential equations are non-linear equations used to simulate this model by using Matlab/Simulink. Proposed model sues d-q variables in a synchronously rotating reference frame. The models have been built up systematically by means of basic function blocks. This is used to study the dynamic performance for any induction motor when it is supplied from a balanced voltage source at starting or at unbalanced voltage source fault conditions. When currents flow in the stator and the rotor windings, arise electromagnetic transient cases which be to ignore, too, will arises dynamic mechanical transient cases, depends on a time constant of the windings. The balanced set of three-phase voltages is:

$$
\begin{aligned}
& V a=V m \sin (w t) \\
& V b=V m \sin (w t-\pi / 3) \\
& V c=V m \sin (w t-2 \pi / 3)
\end{aligned}
$$

To convert a 3-phase voltage (1) to the 2-phase synchronously rotating frame, they are first converted to 2-phase stationary frame $(\alpha, \beta)$ using $(2)$ and then from the stationary frame to the synchronously rotating frame $(d-q)$.

$$
\begin{aligned}
& \left(\begin{array}{l}
V \alpha \\
V \beta
\end{array}\right)=\frac{2}{3}\left(\begin{array}{ccc}
1 & \frac{1}{2} & \frac{-1}{2} \\
0 & \frac{\sqrt{3}}{2} & \frac{-\sqrt{3}}{2}
\end{array}\right)\left(\begin{array}{l}
V a \\
V b \\
V c
\end{array}\right) \\
& \left(\begin{array}{l}
V d \\
V q
\end{array}\right)=\left(\begin{array}{cc}
\operatorname{Cos} \gamma & \operatorname{Sin} \gamma \\
-\operatorname{Sin} \gamma & \operatorname{Cos} \gamma
\end{array}\right)\left(\begin{array}{l}
V \alpha \\
V \beta
\end{array}\right)
\end{aligned}
$$


Where $(\gamma)$ is the transformation angle.

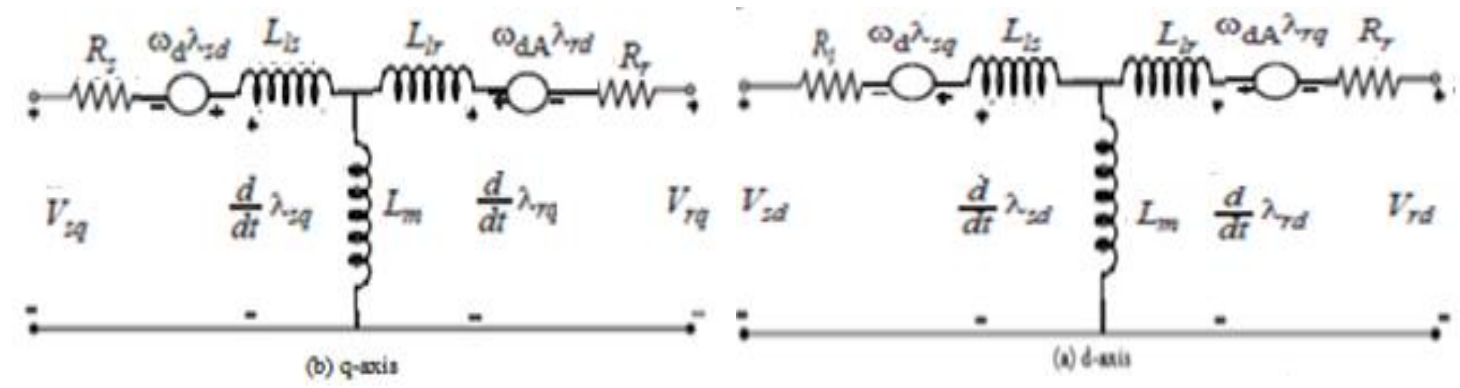

Figure 1. d-q of the dynamic equivalent circuit

Conversion 2-phase to 3-phase (dq-abc) : This conversion does the opposite of (dq-abc) conversion for the current variables using (3) and (4) respectively.

$$
\begin{aligned}
& \left(\begin{array}{l}
i \alpha \\
i \beta
\end{array}\right)=\left(\begin{array}{cc}
\operatorname{Cos} \gamma & \operatorname{Sin} \gamma \\
-\operatorname{Sin} \gamma & \operatorname{Cos} \gamma
\end{array}\right)\left(\begin{array}{l}
i d \\
i q
\end{array}\right) \\
& \left(\begin{array}{l}
i a \\
i b \\
i c
\end{array}\right)=\left(\begin{array}{cc}
1 & 0 \\
\frac{1}{2} & \frac{\sqrt{3}}{2} \\
\frac{-1}{2} & \frac{-\sqrt{3}}{2}
\end{array}\right)\left(\begin{array}{l}
i \alpha \\
i \beta
\end{array}\right)
\end{aligned}
$$

The dynamic equation used:

$$
\begin{aligned}
& \tilde{\mathrm{V} s}=\operatorname{Rs} i \mathrm{~s}+\frac{1}{\omega \mathrm{b}}\left(\frac{d \lambda s}{d t}\right)+\omega \mathrm{e} M\left(\frac{\mathrm{pi}}{2}\right) \lambda_{\mathrm{s}} \\
& \tilde{\mathrm{V}} \mathrm{r}=\operatorname{Rr} i \mathrm{r}+\frac{1}{\omega \mathrm{b}}\left(\frac{d \lambda r}{d t}\right)+(\omega \mathrm{e}-\omega \mathrm{r}) M\left(\frac{\mathrm{pi}}{2}\right) \lambda \mathrm{r}
\end{aligned}
$$

Flux linkage-current relations: $-\chi=\left(\begin{array}{c}\lambda_{\mathrm{S}} \\ \lambda \mathrm{r}\end{array}\right) \boldsymbol{i}=\left(\begin{array}{c}i d \\ i q\end{array}\right)$

$$
\chi_{\mathrm{s}}=\operatorname{Ls} i \mathrm{~s}+\operatorname{Lmir} \chi_{\mathrm{r}}=\operatorname{Lm} i s+\operatorname{Lr} i \mathrm{r}
$$

Where:

$\mathrm{Ls}=\mathrm{Lm}+\mathrm{Ls} 1 \mathrm{Lr}=\mathrm{Lm}+\mathrm{Lr} 1$

Mechanical system (electromagnetic torque) equations:

$$
\begin{aligned}
& \mathrm{T}_{\mathrm{em}}=2 \mathrm{H} \frac{\mathrm{d} \omega_{\mathrm{mec}}}{d t}+\mathrm{B}_{\mathrm{m}} \omega_{\mathrm{mec}}+\mathrm{T}_{\mathrm{L}} \\
& \mathrm{T}_{\mathrm{em}}=2 \mathrm{H} \frac{\mathrm{d} \omega_{\mathrm{mec}}}{d t}+\mathrm{B}_{\mathrm{m}} \omega_{\mathrm{mec}}+\mathrm{T}_{\mathrm{L}} \\
& \omega_{\mathrm{mec}}=\frac{2}{\mathrm{P}} \omega_{\mathrm{r}}:-
\end{aligned}
$$

Where: - $\tilde{\mathrm{V}} \mathrm{s}, \tilde{\mathrm{V} r}$ - voltages space vector of the stator and rotor..is, ir- currents space vector of the stator and rotor. . $\chi_{\mathrm{s}}, \lambda_{\mathrm{r}}$ - flux linkages space vector of the stator and rotor.. $\lambda \mathrm{s}, \lambda \mathrm{r}-$ Flux linkages of the stator and rotor $i$ s. .ir -are the currents of the stator and rotor. .Rs, $\mathrm{Rr}$ - resistances of the stator and rotor. .M(pi/2) Represents a 900space rotor namely. Ls,Lr -stator and rotor inductances..Ls1, Lr1 - stator and rotor leakage inductances. $\mathrm{Lm}$ - magnetization inductance .Tem-electromagnetic torque. TL- load torque. Bm- viscous friction coefficientnumber of poles..i $\alpha$, $i \beta$ - stator and rotor currents $\alpha, \beta$ frame. $\omega$ e - angular velocity of the reference frame . $\omega r$ - 
angular velocity of the rotor. $\omega m e c-$ mechanical angular velocity inertia of the rotor. $\mathrm{V} \alpha, \mathrm{V} \beta$ - stator and rotor voltages $\alpha, \beta$ frame.

\section{SIMULINK MODEL OF INDUCTION MOTOR}

The mathematical dynamic model to study and analysis the dynamic behavior of the induction motor in the $\mathrm{d}-\mathrm{q}$ axes reference is represented by (6) to (10).The linkage fluxes are used as a variable cases to investigate and simulate the dynamic behavior of the motor by Matlab/Simulink. Figure 2 shows the block diagram of three phase induction motor supplied by a 3- phase voltages in the arbitrary frame. The variable $\omega$ $=\omega \mathrm{s}$ represents the synchronous speed of the common reference frame. This block consists, of (a) 3-phase voltage and frequency and (b) abc-dq axes block realizes the transformations of variables defined by (2) and (3). Figure 3 shows the IM-dq- model. This block diagram represents the induction motor using d-q variables axes in an arbitrary reference frame. The IM- d-q model of the motor is represented using (6) and (7) with fluxcurrents relations block. Figure 4 shows the sub-block diagram of flux Linkage-currents relations using ( 8 and 9). It is used to compute the four $d-q$ currents using the four flux linkages and the inverse inductance matrix. The dq- abc block realizes the transformations of variables defined by (4) and (5). Figure 5 shows the mechanical system block determines the electromagnetic torque using (9) transformations of variables determined by (4) and (5). Simulation was done for three phase motor of 5HP , $48 \mathrm{HP}$ and $480 \mathrm{HP}$ motors with supplied by balance voltage and unbalance voltage sources. Motors parameters are presented in Table 1 where each motor has 4-poles and frequency of $50 \mathrm{~Hz}$.

\section{SIMULATION FOR NORMAL OPERATION}

The electromagnetic torque characteristic can be expressed during normal operation through the relationship between the electromagnetic torque and the rotational speed of the motor or slip as shown in Figures 9 and 10.

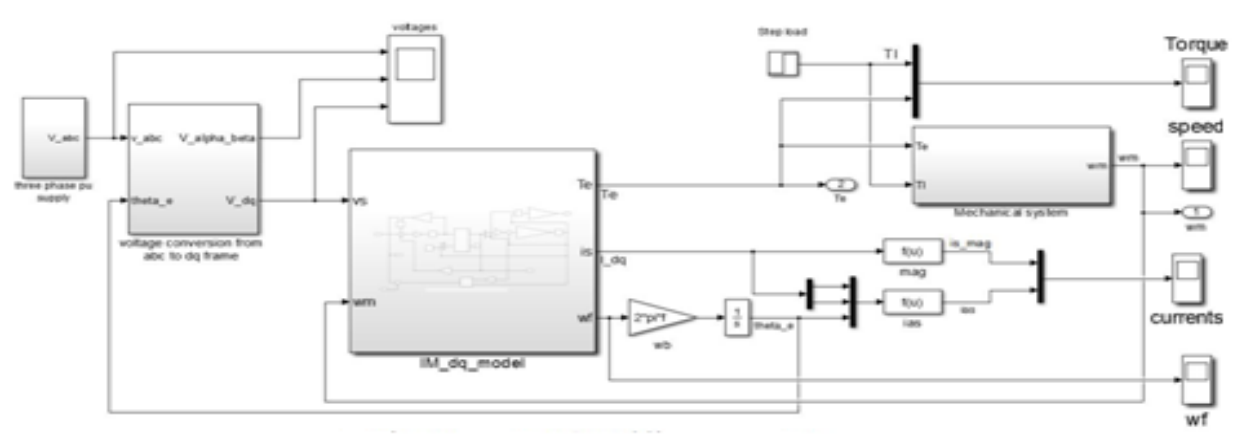

Figure 2. Block diagram of induction motor model in the arbitrary frame

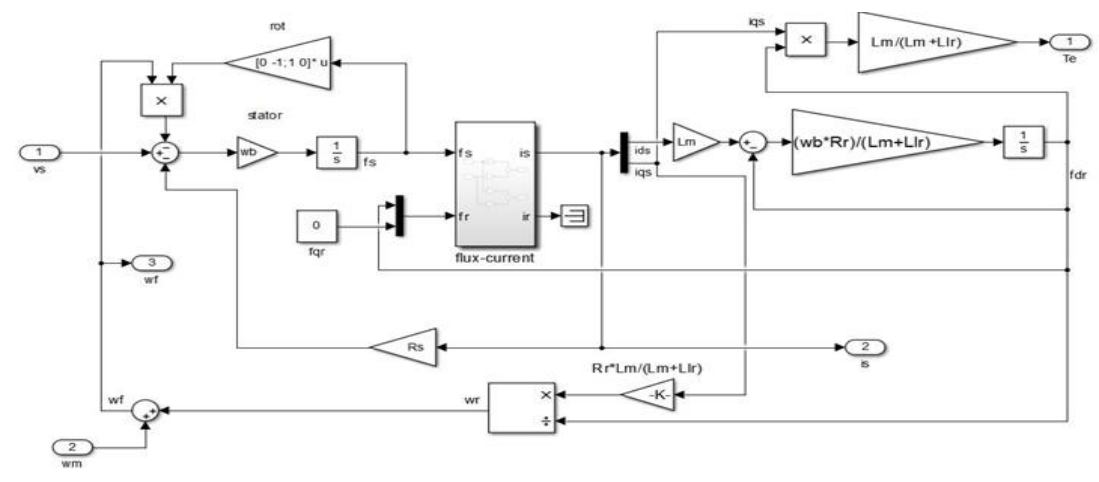

Figure 3. dq-model of induction machine in arbitrary reference frame 


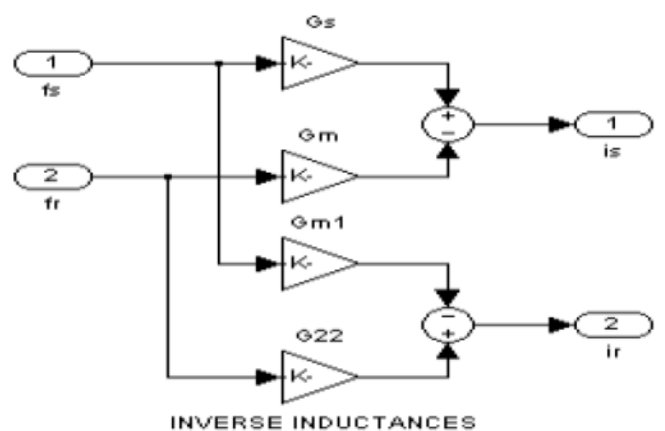

Figure4. Flux-currents relations block

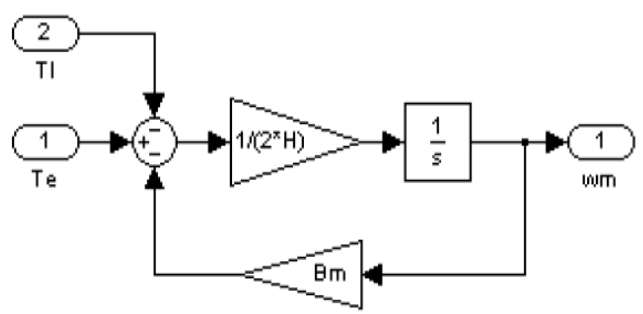

Figure 5.- Mechanical system block

Table 1. Induction Machines Parameters

\begin{tabular}{cccccccccccc}
\hline $\begin{array}{c}\mathrm{HP} \\
(\mathrm{Hp})\end{array}$ & $\begin{array}{c}\text { Volt } \\
(\mathrm{V})\end{array}$ & $\begin{array}{c}\mathrm{RPM} \\
(\mathrm{rpm})\end{array}$ & $\begin{array}{c}\mathrm{T}_{\mathrm{B}} \\
(\mathrm{N} . \mathrm{m})\end{array}$ & $\begin{array}{c}\mathrm{I}_{\mathrm{B}} \\
(\mathrm{A})\end{array}$ & $\begin{array}{c}\mathrm{R}_{\mathrm{S}} \\
(\mathrm{PU})\end{array}$ & $\begin{array}{c}\mathrm{R} ' \mathrm{r} \\
(\mathrm{PU})\end{array}$ & $\begin{array}{c}\mathrm{L}_{1 \mathrm{~S}} \\
(\mathrm{PU})\end{array}$ & $\begin{array}{c}\mathrm{L}_{1 \mathrm{R}}^{\prime} \\
(\mathrm{PU})\end{array}$ & $\begin{array}{c}\mathrm{L}_{\mathrm{M}} \\
(\mathrm{PU})\end{array}$ & $\begin{array}{c}\mathrm{J} \\
\left(\mathrm{Kg} \cdot \mathrm{m}^{2}\right)\end{array}$ & $\begin{array}{c}\mathrm{H} \\
0.091\end{array}$ \\
\hline 5 & 220 & 1430 & 23.6 & 9.8 & 0.021 & 0.038 & 0.0348 & 0.0348 & 1.2 & 0.492 \\
46 & 460 & 1425 & 218.25 & 41.2 & 0.015 & 0.051 & 0.054 & 0.054 & 2.31 & 1.82 & 0.47 \\
480 & 2300 & 1485 & 2215 & 88.2 & 0.018 & 0.013 & 0.082 & 0.082 & 3.8 & 11.02 & 0.4 \\
\hline
\end{tabular}

The outcomes of the survey and analysis of the dynamic behavior of the IM using Matlab/Simulink illustrate the essence of the transient cases such as initiating the motor under load. The electromagnetic torque and currents flowing in the windings of the stator and rotor of the motor appear in a form of cartographic curves as a function of time or speed with a few strikes (inrush), the number of oscillations (pulses) and high peak values because the currents flowing in the motor's windings during a transient case contain two components. The first component is a direct current (DC) and the second is an alternating current (AC). The DC component will be fade to zero at the end of electromagnetic transient cases depending on winding time constant. Analyzing of the effect of the motor parameters in transient cases gives a perception of the quality and characteristic of transient cases and situations for defining the peak value of the torque, strike current and the period of the transient process. At motor starting, a large strike (in-rush) current rises with a few cycles. The strike (in-rush) and oscillations (pulses) currents in the stator are a result of the high instantaneous input current drawn by a motor during the initial starting process, where the induction motor behaves as transformer with a shorted rotor until it begins to rotate. We can observe from the simulation results that at the instant when the motor begins to rotate, a strike (in-rush) and oscillations (pulses) currents arise in the stator. Oscillations and currents consist of two components: AC and DC. The strike currents value, dramatically increase to reach a peak of about 14PU during one cycle with a few number of current oscillations (pulses) having a peak of about 13.5PU for a $5 \mathrm{HP}$ motor .Also, in a $46 \mathrm{HP}$ motor, strike current increases to reach a peak of about 10.6PU during one cycle with a few number of current oscillations having about 9.6PU . The strike current for a 480HP motor is clearly appear and increase to reach about $9.5 \mathrm{PU}$ during one cycle with more number of oscillations current having a peak of about 6.6PU. All oscillations current will disappear when the speed of the motor reaches to synchronous speed. At the end of the transient cases when the motor reaches to synchronous speed, the current arises is the no-load current. Figure 6 shows the behavior of the motor currents and oscillatory currents during startup and normal operation. By increasing the moment of inertia or the HP of the motor, the number of oscillations (pulses) in the Torque- speed characteristic is dramatically increasing at starting with an increase in value until a peak of about (-2 to 2.5) PU and it will disappear when the speed of the motor reaches 0.25 of the synchronous speed, i.e. during a period time of 15 seconds. A few number of oscillations at starting are dramatically increasing to reach a peak of (-1 to 12.35) PU for a 5HP motor and (-3 to 8.35) PU for a $46 \mathrm{HP}$ motor but it will disappear when speed of the motor reaches 0.52 of the synchronous speed, i.e. during a period time of 31 seconds as shown in Figure 7. Figures 6 and 7 show the dynamic behavior of the motor and the oscillatory torques and oscillatory currents during startup and with no-load and at load conditions when the motor supplied by the balanced voltage source. Figure 8 shows the voltage conversion signals. To convert a 3-phase voltage on axes $(\mathrm{a}, \mathrm{b}, \mathrm{c})$ to the 2-phase stationary frame, they are first converted to 2-phase synchronously rotating frame $(\alpha, \beta)$ and then from the synchronously rotating frame to the stationary frame $(\mathrm{d}$, q) where $\mathrm{d}$ - is the direct axis and q- is the quadrant axis. 

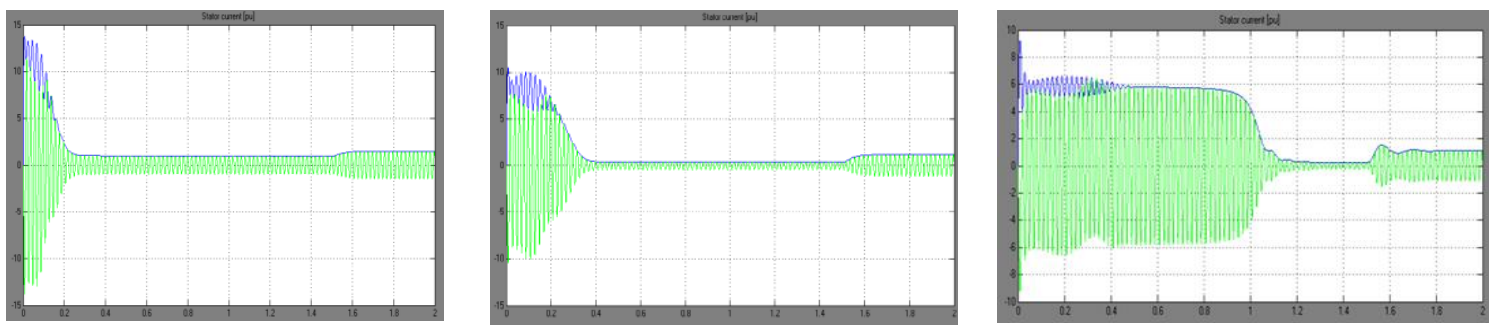

Figure 6. Stator current signal:for a 5HP motor, for a 46HP motor , and for a 480HP motor respectively
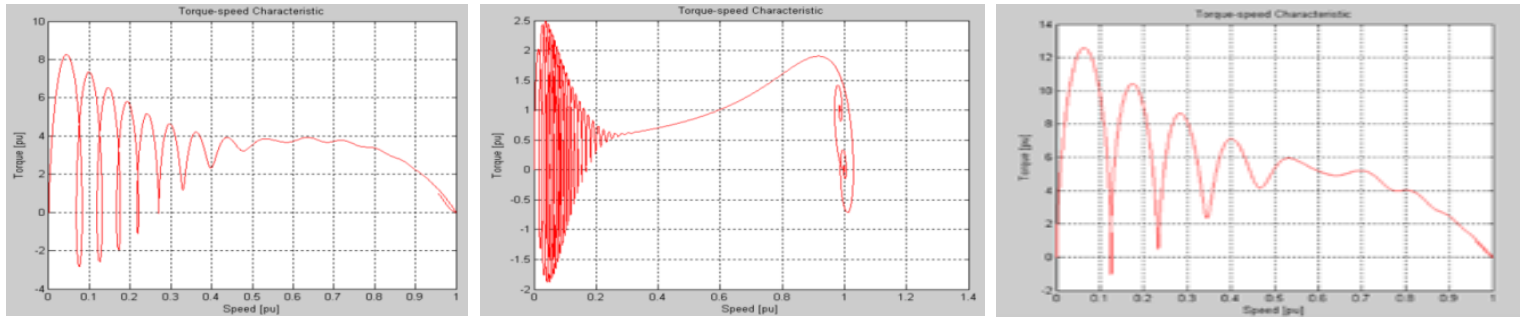

Figure 7. Torque-speed characteristic for a $5 \mathrm{HP}, 46 \mathrm{HP}$, and for a $480 \mathrm{HP}$ motors respectively
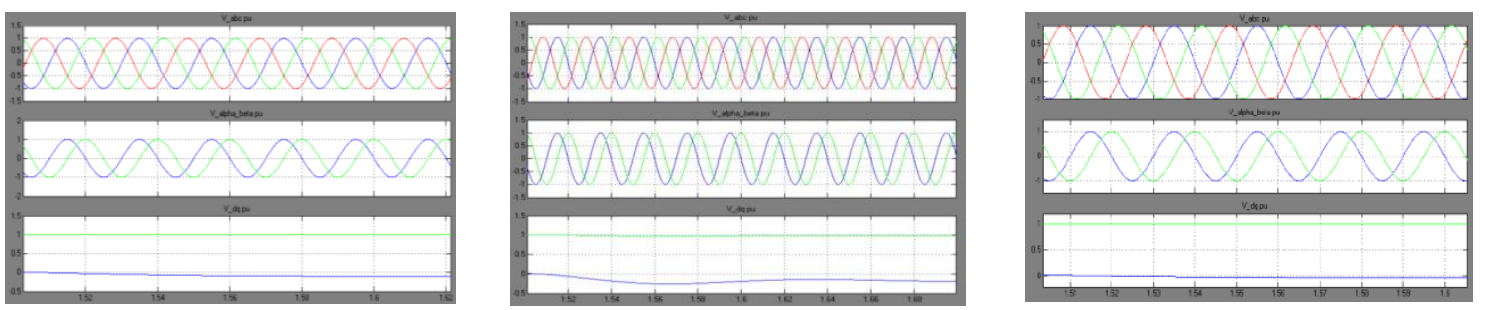

Figure 8. Dynamic performance of the voltage conversion signals (V-abc, $\mathrm{V}-\alpha \beta, \mathrm{V}$-dp) for a $5 \mathrm{hp}, 46 \mathrm{hp}$ and $480 \mathrm{hp}$ induction motors respectively during balanced voltage source(PU)

Figure 9 shows the torque signals. The curves show the three - regions operation of the motor.The first region is a transient case of starting for a low HP motors, this torque has a few oscillations (pulses) with a large peak value having about (12.2) PU for a 5HP motor and about (8.2) PU for a $46 \mathrm{HP}$ motor which disappear quickly in a short time. Merely, in high HP motors, the starting torque has more oscillations (pulses) with peak values having (2.5) PU for a $480 \mathrm{HP}$ motor and they disappear at longer time. The second region shows the no-load torque operation with ignoring the rotational losses initially. The third region shows a load torque operation. Still, in case of the 5-and $46 \mathrm{HP}$ machines, the final operation condition is attained without oscillations. The high power motor of $480 \mathrm{HP}$ has a few oscillations with opposite direction oscillations near the synchronous speed.

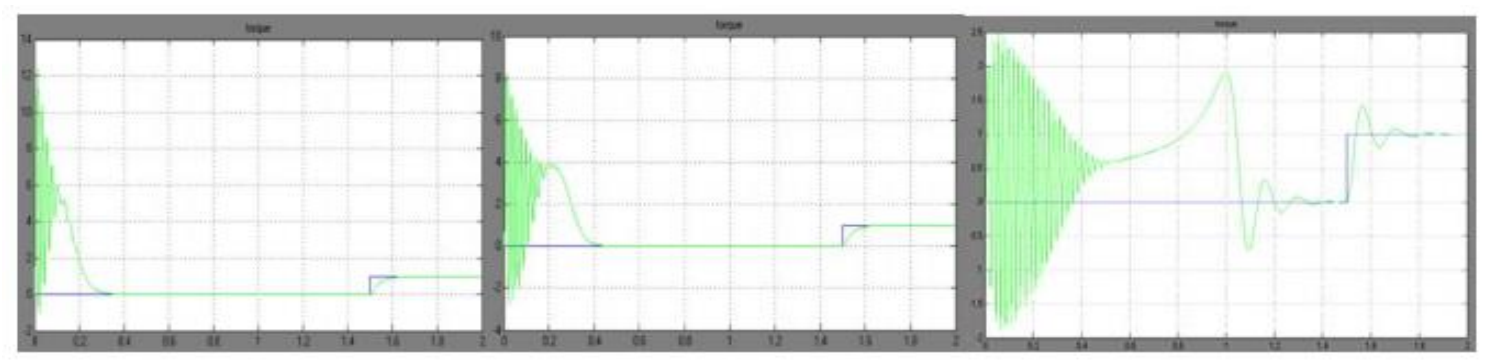

Figure 9. Torque signal characteristic for a 5HP, 46HP, and for a 480HP motors respectively 
When the motor starting at no-load, it will accelerate to turn over the synchronized speed, because the rotational losses are ignored initially. When the speed of the motor reaches or exceeds the synchronized speed, the stator current and the torque will not be equal to zero, but due to the direction of the current flow it becomes braking torque, which leads to reduce the speed of the motor to reach stability at rated speed less than the synchronous speed. For a 5HP and a $46 \mathrm{HP}$ motor, the motor speed reaches the synchronous speed during a few moments of time with a low. Merely for a high HP (480HP) motor, the motor speed reaches the synchronous during more time with a high slip. The speed of the motors is illustrated in Figure 10.

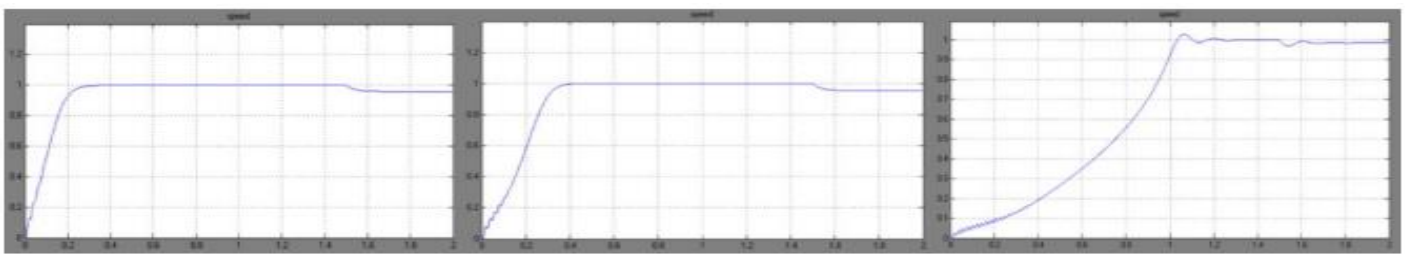

Figure10. Speed signal for a 5HP motor, for a 46HP motor, and for a 480HP motor respectively

\section{INDUCTION MOTOR UNDER UNBALANCED VOLTAGE CONDITION}

In this research the analyzing and calculation of the dynamic- mechanical performance for any induction motor has been done for an unbalanced voltage source during starting process. In this case, we can use the same mathematical models of induction motor (IM) as discussed above to simulate this model by using Matlab/Simulink.Va $=V m \sin (w t)$.

$$
\begin{gathered}
V b=V m \sin (w t-\pi / 3) \\
V c=V m \sin (w t-2 \pi / 3)
\end{gathered}
$$

The same model discussed above has been used to simulate dynamic- mechanical behavior of the induction motor at full load $(\mathrm{TL}=1 \mathrm{PU})$ with unbalanced voltages source $(1 \mathrm{~V}, 0.9 \mathrm{~V}, 0.8 \mathrm{~V})$ for time $(\mathrm{t}=1.5 \mathrm{sec})$ using equations the conversions (2) to (5) from a 3-phase unbalanced voltage to 2-phase synchronously rotating frame $(\alpha, \beta)$ and stationary frame (d, q )- axes as shown in Figure 11. Also, the (6) to (10) were used in mathematical models to analyze and investigate the dynamic behavior of the induction motor supplied by unbalanced voltage source. So the results of the $5 \mathrm{hp}, 46 \mathrm{hp}$ and $480 \mathrm{hp}$ motor simulation fed from an unbalanced voltage source and operated at any transient condition (mechanical torque, currents and rotational speed) have been plotted. At starting when the motor begins to rotate, strike (impulse) current with a large peak rises in the stator. During the start period, a number of oscillations (pulses) of currents and electromagnetic torque appears with peak values approximately equal to the peak values of current oscillations for the motor when its supplied from a balanced voltage.
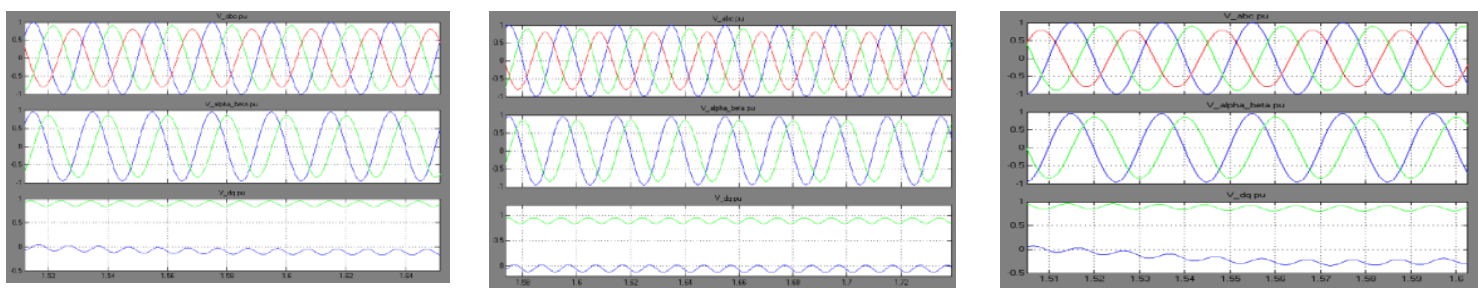

Figure 11. Dynamic performance of the voltage conversion signals ( $\mathrm{V}$-abc, $\mathrm{V}-\alpha \beta, \mathrm{V}$-dp) for a $5 \mathrm{hp}$, 46hp and $480 \mathrm{hp}$ induction motors respectively during unbalanced voltage source

The number of current and torque oscillations in both cases (balanced and unbalanced sources) are different as shown in Figures 12, 13 and 14. These current oscillations disappear when the stator currents reach to a steady state value. The motor speed accelerates until steady state operation in a few moments more than that of balanced source as shown in Figure 14. Also, the peak values of currents and telectromagnetic torques at steady state operation with no-load or load for unbalanced voltage cause appearing of many oscillations with

Implementation simulink modeling to analysis the transient cases and torque ... (Omar M. Al-Barbarawi) 
more peak values. On the contrary, for balanced voltages, oscillations don't appear. The appearing of oscillations leads to the presence of high harmonics and elliptical form of the rotating magnetic field which result in increased heating at full load. Heating may damage the insulation and shorten motor life. Also, varying voltage will result in a noticeable power factor variable. Since electromagnetic torque is proportional to the square of the voltage, therefore, a decrease in electric potential will result in reduction of useable torque. As a result, the motor can't work at steady state operation point. The VA and V $\beta$ don't have the same amplitudes. Therefore, Vd and Vq oscillate because of unbalance voltages. The following figures shows the simulation results obtained by Matlab/Simulink of the investigation of the dynamic behavior of the motor and the oscillatory torques and oscillatory currents during startup, at no-load and at load when the motor operates with unbalanced voltage source.
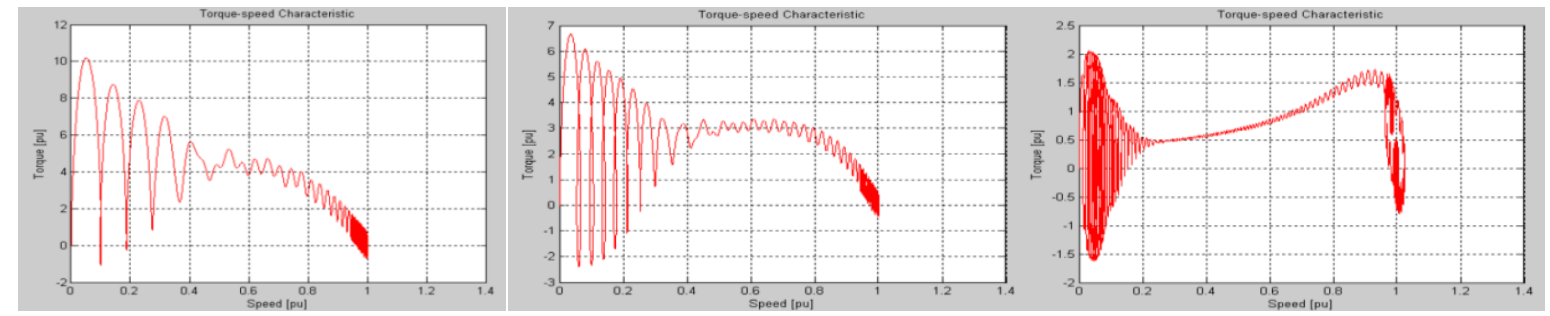

Figure 12. Dynamic performance (torque-speed) for a 3-HP, 50hp and 500hp IM respectively during unbalance voltage (PU)
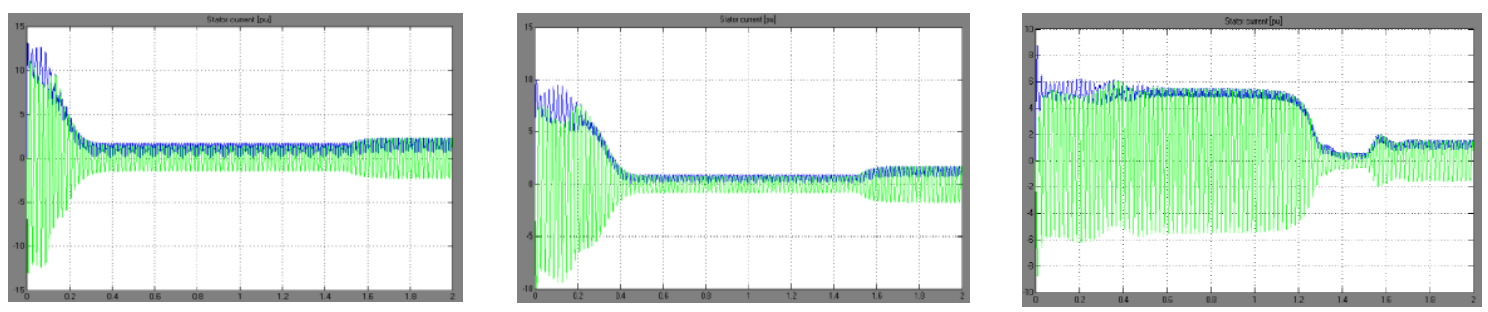

Figure 13. Dynamic performance (stator current characteristic) for a 5-Hp, $46 \mathrm{Hp}$, and $480 \mathrm{Hp} \mathrm{IM}$ respectively during unbalance voltage
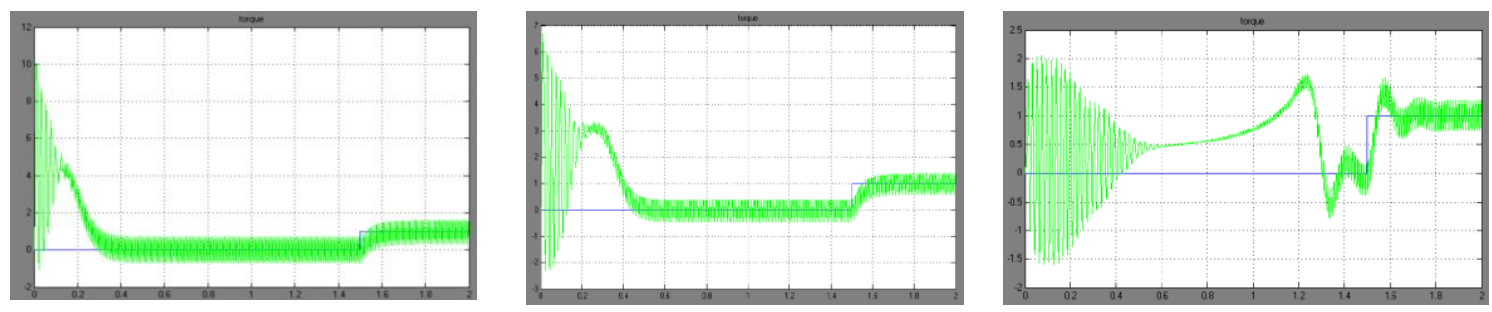

Figure 14. Dynamic performance (torque characteristic) for a $5-\mathrm{Hp}, 46 \mathrm{Hp}$ and $480 \mathrm{Hp}$ IM respectively during unbalance voltage (PU)
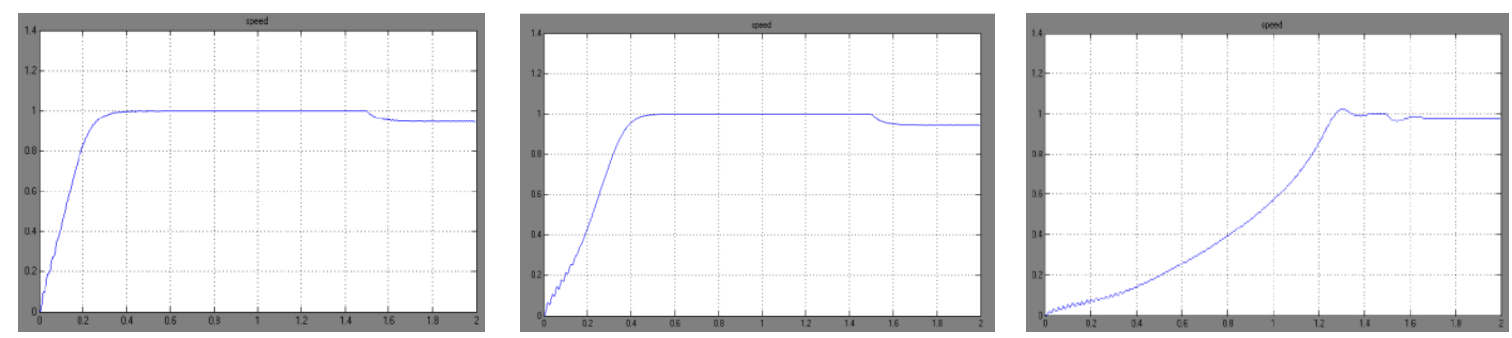

Figure. 15. Dynamic performance (speed characteristic) for a 5-Hp,46Hp, and 480Hp IM respectively during unbalance voltage (PU) 


\section{SIMULINK SOFTWARE OF THE TORQUE-SPEED CHARACTERISTICS}

Any change in electromagnetic torque or in rotor resistance or in feeding voltage, leads to changes in dynamic - mechanical characteristic of the induction machines. Mathematical model uses the over loading capacity factor (OLCF) (KT) equations and the ratio between the conventions of the electromagnetic torque equation and the maximum torque equation (Tem /Tmax). From these equations, we can analysis the effect of various parameters on the operation of a 46HP 3-phase induction motor such as the effect on a Torque - Speed characteristics of a 3-phase induction motor by inserting variable external resistance in series with rotor circuit and changing the supply voltage. The calculation was carried out using (10) and (11). Torque-speed characteristics were calculated by using torque (12) and (13) with parameters in Table 1 for variable supply voltage. The Over Loading Capacity Factor (OLCF) equations are:

$$
\begin{aligned}
& \mathrm{K}_{\mathrm{T}}=\frac{\mathrm{T}_{\mathrm{FL}}}{\mathrm{T}_{\max }}=\frac{2 \mathrm{~S}_{\mathrm{C}} \cdot \mathrm{S}_{\mathrm{FL}}}{\mathrm{S}_{\mathrm{c}}^{2}+\mathrm{S}_{\mathrm{FL}}^{2}}=\mathrm{T}^{*}[\mathrm{pu}] \\
& \mathrm{K}_{\mathrm{T}}=\frac{\mathrm{T}_{\mathrm{FL}}}{\mathrm{T}_{\max }}=\left(\frac{\mathrm{V}}{\mathrm{V}_{\mathrm{N}}}\right)^{2} * \frac{2 \mathrm{~S}_{\mathrm{C}} \cdot \mathrm{S}_{\mathrm{FL}}}{\mathrm{S}_{\mathrm{C}}^{2}+\mathrm{S}_{\mathrm{FL}}^{2}}=\mathrm{T}^{*}[\mathrm{pu}]
\end{aligned}
$$

Full load torque and maximum torque equations:

$$
\begin{gathered}
\mathrm{T}_{\mathrm{FL}}=\frac{3 \mathrm{~V}_{\mathrm{ph}}^{2} \cdot \mathrm{R}_{2}^{\prime}}{\mathrm{S}_{\mathrm{FL}} \cdot \omega_{\mathrm{S}}\left[\left(\mathrm{R}_{1}+\mathrm{R}_{2}^{\prime} / \mathrm{S}_{\mathrm{FL}}\right)^{2}+\left(\mathrm{X}_{1}+\mathrm{X}_{2}^{\prime}\right)^{2}\right]} \\
\mathrm{T}_{\max }=\frac{3 \mathrm{~V}_{\mathrm{ph}}^{2} \cdot \mathrm{R}_{2}^{\prime}}{\mathrm{S}_{\mathrm{C}} \cdot \omega_{\mathrm{S}}\left[\left(\mathrm{R}_{1}+\mathrm{R}_{2}^{\prime} / \mathrm{S}_{\mathrm{C}}\right)^{2}+\left(\mathrm{X}_{1}+\mathrm{X}_{2}^{\prime}\right)^{2}\right]}
\end{gathered}
$$

Where: SFL, SC - Full load slip and critical slip .R1, R'2, stator and rotor resistances. X1,X'2- stator and rotor inductances. Figure 16 shows a Torque-Speed characteristics of three - phase IM using the OLCF (10) and (11) with a variable external resistances inserted into the rotor circuit and when one phase is separated from a motor supply. Figure 17 shows a Torque-Speed characteristics of three - phase IM using the ratio between the conventional (11) and (12) (Tem /Tmax) when motor operating under different conditions by varying voltage or by inserting external resistance in the rotor circuit. Figure 18: Shows the Torque-Speed characteristics of three - phase IM in motoring, and braking modes using the OLCF Equations for variable external resistances inserted into the rotor circuit to reduce the start current, to increase the starting torque until Tmax and to control the motor speed.
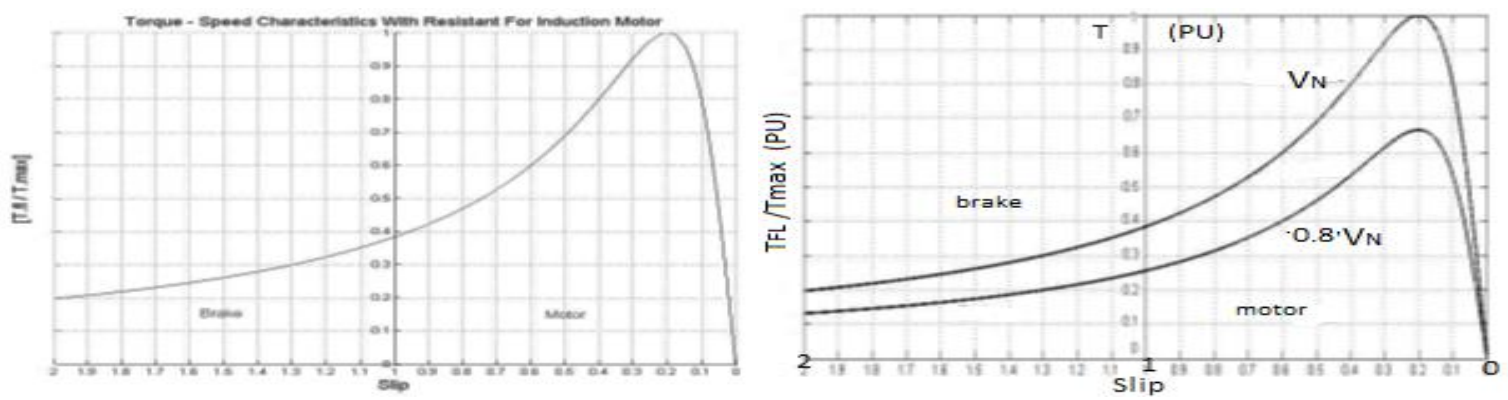

Figure 16. Torque-Speed characteristics of three - phase IM, with variable resistances in rotor circuit, and when fail one phase 

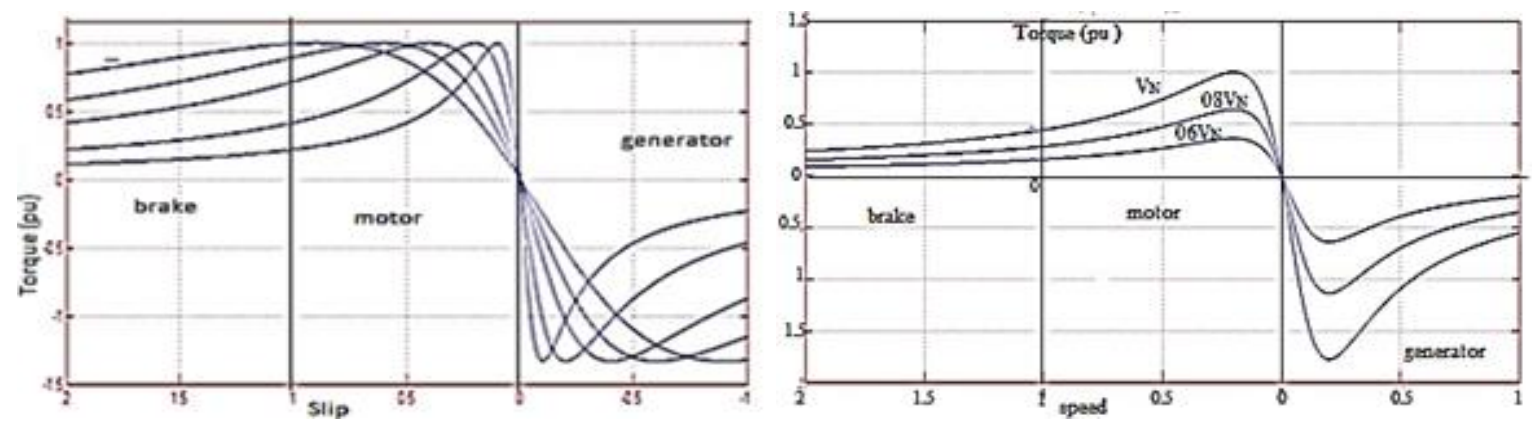

Figure 17. Torque-Speed characteristics of a 3-phase IM showing, braking, motoring and generating regions by using $[\mathrm{Tem} / \mathrm{Tmax}]$ with a variable rotor resistances and with variable stator voltage
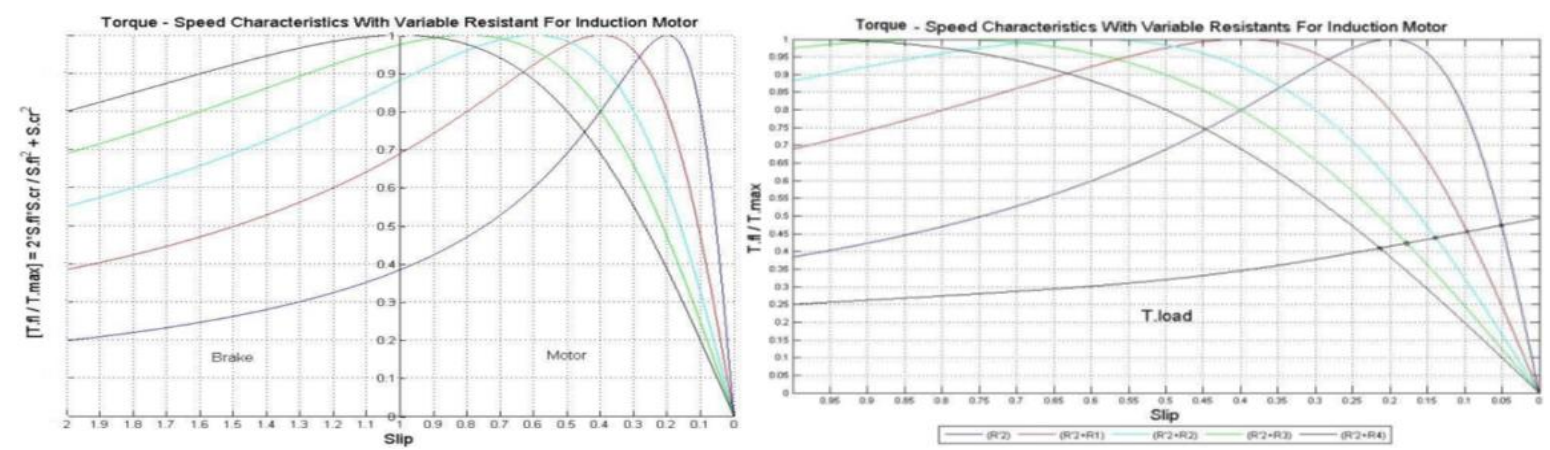

Figure 18. Torque-Speed characteristics of three - phase IM, showing motoring region, and both motoring and braking regions using the OLCF Equations with a variable resistances in the rotor circuit

\section{CONCLUSION}

From the above analysis and the simulation results, we notice that when the induction motor operates at load or no-load during starting process or other transient conditions, it behaves as a transformer with shorted circuit in the secondary windings. At starting, strikes (in-rushes) current arises and electromagnetic torque dramatically increases until a high amplitude value during one cycle pulse. This strike of current clearly appears in high power motors. Because the currents formed during the transient cases at starting, braking or unbalancing voltage are equivalent to the short circuit current which consists of two components. These components are direct current (DC) component and alternating current (AC) component. Once the rotor begins to rotate, current oscillations and electromagnetic torque oscillations appear in motor until the motor reaches its rated speed. Also, through starting process, the rotating magnetic field induces back-EMF in the stator windings which leads to decrease the currents till the rated value at steady state.

For low-power motors, currents and the electromagnetic torque increase to reach high values with a few numbers of a oscillations, and disappear faster during a short period of time. For high-power motors, currents oscillations in the stator and electromagnetic torque oscillations during the starting process have a greater number with smaller amplitude values and it will disappear during a long period of time. All oscillations and DC component will be faded when motor reaches steady states condition. As the speed of the motor becomes higher than the synchronous speed, the torque changes its sig and the motor operates in the generating mode. Finally, the speed decreases and the machine returns again to operate as a motor with rated speed less than synchronous speed as shown in figures above. The same behavior repeats when the motor is supplied from unbalanced voltage during transient and steady - state conditions. The faded of the DC component has more period time than that of the balanced voltage are source. The repeated short spikes of current may result in the unnecessary tripping of fault devices. Inserting a resistance into the rotor circuit will decrease the starting current, increase the starting torque even to the maximum motor torque and improve the power factor. The external resistance will be removed when the motor reaches its nominal speed to increase the motor efficiency. 


\section{REFERENCES}

[1] K. Vinoth Kumar, S. Suresh Kumar, and A. Immanuel Selvakumar, "A review of voltage and current signature diagnosis in industrial drives," International Journal of Power Electronics and Drive Systems (IJPEDS), Vol.1, No.1, September 2011, pp. 75-82 ISSN: 2088-8694.

[2] O. M. Albarbarawi . A. Y. Al-Rawashdeh . G. Qaryouti, "Simulink Modelling of the Transient Cases of Three Phase Induction Motors" International Journal of Electrical \& Computer Sciences IJECS-IJENS, Vol:17 No:04 , pp 1-10, August 2017.

[3] Aderibigbe Israel Adekitan, Adeyinka Adewale, Alashiri Olaitan, " Determining the operational status of a three phase induction motor using a predictive data mining model" International Journal of Power Electronics and Drive System (IJPEDS) Vol. 10, No. 1, March 2019, pp. 93 103 ISSN: 2088-8694.

[4] K.L. Shi, T.F. Chan, Y.K. Wong and S.L. Ho, "Modeling and simulation of the three- phase induction motor using Simulink", International Journal of Electrical Engineering Education, Vol. 36 (1999), pp. 163-172.

[5] S. Shahbudin, Z. F. Mohmad, S. I. Suliman, M. Kassim, and R. Mohamad, "Classification of power quality disturbances at transmission system using support vector machines," Indonesian Journal of Electrical Engineering and Computer Science (IJEECS), vol. 6, pp. 310-317, 2017.

[6] B. Ospineci and L.M. Tolbert, "Simulink Implementation of Induction Machine Model-A Modular approach", IEEE International Electric machines and drives conference (IEMDC), Vol.2 (2003), pp. 728-734.

[7] K.S Sandhu and VivekPahwa, "Simulation study of Three Phase induction motor with variations in moment of inertia”, ARPN Journal of Engineering and Applied Sciences, vol. 4, No. 6, August 2009, pp-72-77.

[8] Wade, S., Dunnigan, M. W. and Williams, B. W., "Modeling and simulation of inductionmachine vector control and rotor resistance identification”, IEEE T rans. Power Electronics, Vol. 12, No. 3, pp. 495-505 (1997) 172.

[9] M. Jannati, et al., "Indirect rotor field-oriented control of fault-tolerant drive system for three-phase induction motor with rotor resistance estimation using EKF," Indonesian Journal of Electrical Engineering and Computer Science (IJEECS), vol. 12, pp. 6633-6643, 2014.-734.

[10] S. Wade, M.W. Dunnigan and B.M. Williams, "Modeling and simulation of induction machine vector control with rotor resistance identification", IEEE Transactions on Power Electronics, Vol. 12, No. 3 (1997), pp. 495-506.

[11] Boldea and S.A. Nasar: Electric Drives, CRC Press, Florida, USA, (1998).

[12] P. C. Krause, O. Wasynczuk and S. D. Sudhoff, "Analysis of Electric Machinery and Drive Systems," IEEE Press Series on Power Engineering, John Wiley and Sons, Inc., New Jersey, 2004.

[13] V. Pahwa and K. S. S, "Three-Phase Induction Machine Using Different Reference Frames," ARPN Journal, Vol. 4, No. 8, 2009, pp. 31-38.

[14] Afrah Thamer Abdullah, Dr. Amer Mejbel Ali “ Thermal analysis of a three-phase induction motor based onmotorCAD, flux2D, and matlab "Indonesian Journal of Electrical Engineering and Computer Science (IJEECS), Vol. 15, No. 1, July 2019, pp. 46-53 ISSN: 2502-4752.

[15] H.F. Abdul-Wahab and H. Sanusi, "Simulink Model of Direct Torque Control of Induction Machine", American Journal of Applied Sciences, Vol. 5 (8) (2008), pp. 1083-1090.

[16] C. U. O, "Method of Induction Motor Transient and Steady State Analysis," The Pacific Journal of Science and Technology, Vol. 10, No. 1, 2009, pp. 59-66.

[17] C.F. Landy, "The prediction of transient torques produced in induction motors due to rapid reconnection of the supply”, SAIEE. Trans, Vol.112, No.7, 1965, pp.1348-1354.

[18] K.S.Sandhu, A.V.J.S.Praneeth, A.V.S.S.S.Pradeep "Transient Analysis of Three Phase Induction Machine With Unbalanced Supply," IOSR Journal of Engineering, 9Vol. 3, Issue 10 (October. 2013), ||V4|| PP 49-58.

\section{BIOGRAPHIES OF AUTHORS}

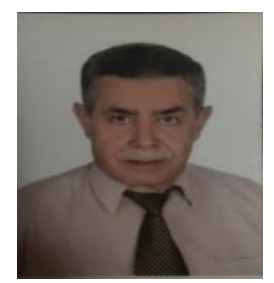

Dr. Omar M. AL-Barbarawi Hebron/Jordan/Jordanian Phd. Electrical power Engineering, specialization electrical machines, Energetics institute -Moscow - USSR -1986 Department, Faculty of Engineering Technology/Al-Balqa' Applied University. Jordan/Amman.

Email:omaralbarbarawi@bau.edu.jo

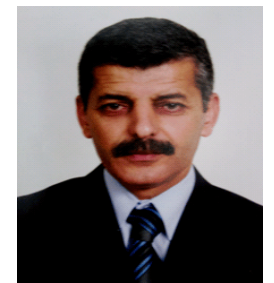

Ghazi M. Qaryouti; received his B.Sc. in electrical Engineering from Damascus university in 1982, and M.S in Mechatronics Engineering from Al-Balqa' Applied University Jordan in 2006, and Ph.D. degrees in Mechatronics Engineering from De Montfort University in Leicester, UK in 2015 His research interests are in Power Electronics and Electric Machines and Drives, Energy Efficiency and Management, and Renewable System

Email: ghazi_qaryouti@bau.edu.jo 